DOI: $10.1002 /$ ente.201600024

Full Paper

\title{
Combined Calcium Looping and Chemical Looping Combustion for Postcombustion Carbon Dioxide Capture: Process Simulation and Sensitivity Analysis
}

Benoit Duhoux, ${ }^{[a]}$ Dr. Poupak Mehrani, ${ }^{[a]}$ Dr. Dennis Y. Lu, ${ }^{[b]}$ Robert T. Symonds, ${ }^{[b]}$ Dr. Edward J. Anthony, ${ }^{[\mathrm{c}]}$ and Dr. Arturo Macchi* ${ }^{[\mathrm{a}]}$

[a] Department of Chemical and Biological Engineering University of Ottawa, 161 Louis Pasteur Street

Ottawa, Ontario K1N 6N5 (Canada)

Fax: $(+1) 613.562 .5172$

E-mail:arturo.macchi@uottawa.ca

[b] Natural Resources Canada, CanmetENERGY

1 Haanel Drive, Ottawa, Ontario K1A 1 M1 (Canada)

[c] School of Applied Science, Cranfield University

Cranfield, Bedfordshire MK43 OAL (UK)

spi This manuscript is part of a Special Issue on Chemical Looping Combustion. A link to the Special Issue's full Table of Contents will appear here once the issue is complete.

Taking C down! Process simulations of calcium looping based carbon capture processes are performed to obtain thermodynamic process performance indicators. The integration of chemical looping combustion in a hybrid process is implemented to avoid high-purity oxygen production and multiple capture process layouts are tested. The use of the hybrid process results in a reduction of the penalty on power production.

@uOttawa@CranfieldUni Simulating \#carboncapture in \#calcium and \#chemical looping processes 


\begin{abstract}
calcium
carbon storage

chemical looping

combustion

process simulation

In this work, a combined calcium looping and chemical looping combustion (CaL--CLC) technology is simulated at thermodynamic equilibrium conditions and the results in terms of efficiency, power production, and solids circulation rates are compared with the case of using $\mathrm{CaL}$ alone. In addition, a new solids looping configuration in the CaL--CLC process is proposed with the purpose of mitigating the loss of calcium oxide conversion after high cycle numbers. Simulations show an improved process efficiency of the CaL--CLC method compared with CaL alone (34.2 vs. $31.2 \%$ higher heat value) and an increased power output (136 vs. $110 \mathrm{MW}_{\mathrm{e}}$ additional power) due to the higher energy requirement to preheat the reactants. A sensitivity analysis of the process operating parameters highlights the particular importance of the temperature difference between reactors, which has a strong impact on the required mass of solids circulating in the loops. Finally, partial carbon dioxide capture scenarios are considered and indicate that lower capture levels are suitable to match regulation targets.
\end{abstract}

\title{
Introduction
}

The combustion of fossil fuels represents the major source of energy for electricity production in the world. In 2012, approximatively $67 \%$ of world production relied on fossil fuels, with coal alone accounting for about $41 \%$ of the global power output. ${ }^{[1]}$ Although energy production predictions foresee a shift towards renewable sources of energy (e.g., solar, hydro, wind), fossil fuels and coal, in particular, will still constitute an important source of energy. ${ }^{[2]}$ 
Compared with coal, natural gas represents a cleaner source of energy because it is less carbon intensive. Coal also contains more sulfur and generates ashes and a range of micropollutants. Coal and oil-fired power plants, with $\mathrm{CO}_{2}$ intensities of about 900 and 600 $\mathrm{kg} \mathrm{CO}_{2} \mathrm{MW}_{\mathrm{e}}^{\mathrm{M}-1} \mathrm{~h}^{\mathrm{M}-1}$, respectively, appear to be the first stationary carbon sources in which carbon capture and sequestration (CCS) should be employed. ${ }^{[3]}$ Indeed, recent regulations in Canada and in the USA could push carbon emission from coal power plants to the level of the natural gas fired combined cycle $\left(\approx 400 \mathrm{~kg} \mathrm{CO}_{2} /\right.$ in $\left.\mathrm{MW}_{\mathrm{e}}{ }^{\mathrm{M}-1} \mathrm{~h}^{\mathrm{M}-1}\right) .{ }^{[3-5]}$ Based on this data, lowering the $\mathrm{CO}_{2}$ emissions of coal-based power plants to such levels is not feasible without the implementation of a carbon capture process.

Postcombustion $\mathrm{CO}_{2}$ capture technologies are the only "end-of-pipe" solutions that would allow the mitigation of carbon emissions from stationary sources without the need for major modifications to the power plant itself. The most mature capture technology is the absorption of $\mathrm{CO}_{2}$ by amine solutions, but this process requires a significant amount of power, which reduces the output of the power plant and its efficiency. ${ }^{[6,7]}$ Reactive solids processes, however, make use of high-temperature reactions and allow the recovery of high-quality heat to produce more electricity. ${ }^{[6,8,9]}$

Calcium looping $(\mathrm{CaL})$ is a specific implementation of a reactive solids process. It uses the reversible carbonation reaction by circulating calcium oxide based solids between two reactors operating at different temperatures. The lower temperature in the carbonation reactor causes the formation of calcium carbonate [Reaction (1)], which reduces the amount of $\mathrm{CO}_{2}$ released by the plant, whereas the higher temperature of the calciner regenerates the sorbent and releases $\mathrm{CO}_{2}$ [Reaction (2)]. ffr1 ffr2

$$
\begin{aligned}
& \text { ffl } \mathrm{CaO}+\mathrm{CO}_{2} \rightarrow \mathrm{CaCO}_{3} \_\Delta H 650^{\circ} \mathrm{C} / \mathrm{in}=\mathrm{M}-172.4 \mathrm{~kJ} \mathrm{~mol}^{\mathrm{M}-1} \mathrm{ZS}(1) \\
& \mathrm{ff} 2 \mathrm{CaCO}_{3} \rightarrow \mathrm{CaO}+\mathrm{CO}_{2} \_\Delta H 900^{\circ} \mathrm{C} / \mathrm{in}=166.2 \mathrm{~kJ} \mathrm{~mol}^{\mathrm{M}-1} \mathrm{ZS}(2)
\end{aligned}
$$

This technology has been intensively investigated. Laboratory experiments first provided proof-of-concept results, understanding of reaction mechanism, and investigation of 
sorbent performances. ${ }^{[10-18]}$ Process simulation, ${ }^{[19-23]}$ reactor modeling, ${ }^{[24--29]}$ and economic analysis $^{[19,30]}$ helped to show the potential of the process and its feasibility. Several pilot plants have been constructed with capacities ranging from $75 \mathrm{~kW}_{\text {th }}$ up to $1.7 \mathrm{MW}_{\text {th }}$; the latter treated a fraction of the flue gas from an existing $50 \mathrm{MW}_{\mathrm{e}}$ circulating fluidized-bed combustion $\quad\left(\right.$ CFBC) power plant. ${ }^{[31-35]}$ The results of the operation of these systems showed that the process was able to reach capture efficiencies above $90 \%{ }^{[31,32,34]}$ Deactivation of the sorbent ${ }^{[31,32]}$ and particle loss due to attrition ${ }^{[34]}$ caused the capture efficiency to decrease, but it remained at an acceptable level (above $75 \%$ in Ref.). In addition, adaptation of the bed inventory can compensate for the sorbent capacity drop. ${ }^{[32]}$ Calcium oxide also reacts with $\mathrm{SO}_{2}$ and could serve as a sulfur removal method. However, the irreversibility of sulfation of calcium oxide under the operating conditions significantly affects the extent of the carbonation reaction. ${ }^{[32,34,36]}$

To improve the conversion of sorbent particles, calcium oxide can be pelletized with a cement support. Pelletized sorbents are less susceptible to attrition ${ }^{[37]}$ and the use of calcium aluminate cement as a binder can increase the conversion of calcium oxide. ${ }^{[38,39]}$ This is especially true at high cycle numbers at which the formation of $\mathrm{CaO} C-\mathrm{Al}_{2} \mathrm{O}_{3}$ compounds stabilizes the structure of the sorbent, making it more resistant to sintering. ${ }^{[38-40]}$

The CaL calciner is operated under oxycombustion conditions to avoid the dilution of carbon dioxide by nitrogen, and thus, requires the implementation of an air separation unit (ASU). Along with the $\mathrm{CO}_{2}$ compression train, the ASU is another significant contributor to the energy penalty of the capture process. ${ }^{[21,22]}$ An alternative to the operation of the calciner under oxyfuel conditions is chemical looping combustion (CLC), which uses a solid oxygen carrier to avoid direct contact between air and the fuel (Scheme 1). ${ }^{[41]}$ A metal oxide carries oxygen in a solid form to the fuel reactor where it is reduced by reacting with the fuel [Reaction (3) for copper]; in this case, methane. The reduced solids are then transferred to an air reactor where air is used to re-oxidize the metal back to its original higher oxidation state 
[Reaction (4) for copper]. Although a fluidized-bed reactor system is discussed herein, the process can also be achieved in a fixed-bed configuration. ${ }^{[41]} \mathrm{ffr} 3 \mathrm{ffr} 4 \mathrm{ffr} 5$

$$
\begin{aligned}
& \text { ff3 } 4 \mathrm{CuO}+\mathrm{CH}_{4} \rightarrow 4 \mathrm{Cu}+\mathrm{CO}_{2}+\mathrm{H}_{2} \mathrm{O}+\Delta H 900{ }^{\circ} \mathrm{C} / \text { in }=\mathrm{M}-201.5 \mathrm{~kJ} \mathrm{~mol}{ }^{\mathrm{M}-1} \mathrm{ZS}(3) \\
& \text { ff4 } \mathrm{Cu}+0.5 \mathrm{O}_{2} \rightarrow \mathrm{CuO}+\Delta H 950{ }^{\circ} \mathrm{C} / \text { in }=\mathrm{M}-149.7 \mathrm{~kJ} \mathrm{~mol}{ }^{\mathrm{M}-1} \mathrm{ZS}(4) \\
& \text { ff5 } \mathrm{CH}_{4}+2 \mathrm{O}_{2} \rightarrow \mathrm{CO}_{2}+2 \mathrm{H}_{2} \mathrm{O}+\Delta H 900{ }^{\circ} \mathrm{C} / \text { in }=\mathrm{M}-802.3 \mathrm{~kJ} \text { mol }{ }^{\mathrm{M}-1} \mathrm{ZS}(5)
\end{aligned}
$$

The energy released in the two-reactor system is equivalent to the direct combustion of the fuel [Reaction (5)], but the distribution of that energy between the air and fuel reactors depends on the chosen fuel and oxygen carrier. ${ }^{[9,41]}$ The choice of the solid carrier depends on multiple factors: the reactivity with the fuel, its oxygen carrying capacity, its resistance to attrition, its tendency to agglomerate, its toxicity, and price. Commonly used carriers include copper, nickel, cobalt, manganese, and iron oxides. ${ }^{[9,41,42]}$

When $\mathrm{CaL}$ and CLC are coupled, the resulting process consists of three reactors (Scheme 2) and the solids circulating between them are a composite of $\mathrm{CaO}$, the oxygen carrier, and a binder. In the calciner, $\mathrm{CaO}$ is regenerated by using energy produced by the reaction between the metal oxide and the fuel. This can only be achieved if the reduction of the oxygen carrier by the fuel is an exothermic reaction, which constitutes another important parameter to consider when choosing the right sorbent formulation. Manovic and Anthony performed a screening of potential oxygen carriers suitable for a combined CaL--CLC process. ${ }^{[42]}$ Multiple metals and fuels were included in their analysis and the $\mathrm{Cu} / \mathrm{CuO}$ system was chosen as an ideal candidate, mostly because of its fast reaction kinetics and the high ratio of energy produced per unit mass of carrier when reduced by methane, which was the fuel most likely to be used. Despite its advantages, the choice of copper as an oxygen carrier also raises concern about particle agglomeration due to the low melting point of metallic copper $\left(1085^{\circ} \mathrm{C}\right)$. However, studies have shown that, by changing the loading of copper in the solid particles or the pellet manufacturing method, this problem could be avoided, and agglomeration of the particles could be avoided up to $950{ }^{\circ} \mathrm{C} .{ }^{[43,44]}$ 
The combined CaL--CLC process conducted in fluidized-bed reactors was simulated in AspenONE®. This process has previously been simulated for steam--methane reforming in a fixed-bed configuration. ${ }^{[45,48]}$ Although fixed beds are easier to operate, fluidized-bed reactors were chosen in this work due to the mitigated risk of hot spots ${ }^{[47]}$ and the continuous need for fresh sorbent addition. Moreover, the operation of fluidized beds generates a continuous feed of $\mathrm{CO}_{2}$ to the compression train, whereas fixed beds would require the installation of multiple units to achieve such an operation. Ozcan et al. conducted the preliminary process simulation on a combined CaL--CLC in fluidized-bed reactors by using $\mathrm{CaO}$ C- $\mathrm{CuO}$ C- $\mathrm{Al}_{2} \mathrm{O}_{3}$ composite pellets and compared this capture process to oxycombustion, CaL, and amine scrubbing. ${ }^{[48]}$ The combined CaL--CLC process consistently has 2 to $5 \%$ higher efficiencies than the other technologies. The present study expands on this first work by providing a more detailed sensitivity analysis, in addition to proposing a new configuration of the solids looping process.

When operating the CaL--CLC process, most of the energy from the fuel is released in the air reactor [see Reactions (3) and (4)]. The implemented solution in that work was then to operate the air reactor at higher temperature and circulate hot solids back to the calciner to transfer additional energy through the sensible heat of the solids. Although effective, this modification significantly increases the solids circulation rate and the sorbent particles are exposed to high temperatures in the air reactor. To limit sorbent sintering due to temperature effects and reduce the solids flow rate, a new configuration of the process is presented herein, in which the calcium and copper species are separated into two distinct particles and circulated in two loops. The $\mathrm{CaL}$ and the two configurations of CaL--CLC are studied through a sensitivity analysis on parameters, including reactor temperatures, sorbent performance, and overall $\mathrm{CO}_{2}$ capture target.

\section{Results and Discussion}

\section{Base case conditions}


The simulation base case parameters are listed in Table 1. These parameters are chosen to obtain favorable conditions in the reactors for the capture and release of $\mathrm{CO}_{2}$, with a low carbonator temperature and a high calciner temperature. The solid make-up ratio is defined by Equation (1): ffr6

ff6 Make-up dp ratio $=\frac{F_{0}}{F_{\mathrm{CO}_{2}}}+\mathrm{dp}=\frac{\text { Molar }^{\wedge} \text { flow }^{\wedge} \text { rate }^{\wedge} \mathrm{of}^{\wedge} \mathrm{CaCO}_{3}^{\wedge} \mathrm{in}^{\wedge} \text { make }- \text { up }^{\wedge} \text { stream }}{\text { Molar }^{\wedge} \text { flow }^{\wedge} \text { rate }^{\wedge} \mathrm{of}^{\wedge} \mathrm{CO}_{2}{ }^{\wedge} \text { in }^{\wedge} \text { flue }^{\wedge} \text { gas }^{\wedge} \text { carbonator }}$ ZS (1)

Both $F_{0}$ and $F_{\mathrm{R}}$ (the molar flow rate of $\mathrm{CaO}$ entering the carbonator) affect the conversion that the sorbent reaches in the carbonator because they determine the number of cycles the sorbent particles will go through, according to Equation (2): ${ }^{[11]} \mathrm{ffr} 7$

$$
\mathrm{ff7} r_{N}=\frac{F_{0} F_{\mathrm{R}}^{N-1}}{\left(F_{0}+F_{\mathrm{R}}\right)^{N}} \mathrm{ZS}
$$

in which $r_{N}$ is the fraction of solids entering the carbonator that went through $N$ cycles.

The adjustment of the make-up ratio and the solids circulation flow rate, depending on the sorbent conversion decay, allow a desired average conversion to be obtained. Because there is no reactor modeling in the simulation, the make-up ratio is fixed to 0.1 to match the work by Ozcan et al. ${ }^{[48]}$ and represent an average from a previous simulation study by Alonso et al. ${ }^{[25]}$ A partial capture scenario was chosen for the base case because it would be sufficient to meet current emission regulations. ${ }^{[4,5]}$ The flue gas composition and flow rate is described in the Computational Details section.

Each reactor operates at atmospheric pressure and has an assumed pressure drop of 20 $\mathrm{kPa}$. Boosters are used to increase the pressure of the gaseous feed streams and overcome the pressure drop.

\section{Base case simulation}

The base case results provide a first comparison between $\mathrm{CaL}$ and both configurations of the combined CaL--CLC. Tables 2 and 3 present key results from the three capture 
process configurations. Notably, all reported solids flow rates correspond to the highest flow rate observed in the process. This corresponds to the outlet of the carbonator for $\mathrm{CaL}$, the outlet of the air reactor for the CaL--CLC single loop, and the outlets of the calciner and air reactor for the CaL--CLC dual loop.

Carbon dioxide capture processes based on $\mathrm{CaL}$ are able to generate a significant amount of additional power if energy is recovered from the high-temperature reactors and streams. In this particular study, a secondary steam cycle is used to that end and produces additional electrical power. Compared with the base power plant output of $550 \mathrm{MW}_{\mathrm{e}}$, the implementation of the capture process yields a 19--21\% increase in power production, depending on the configuration used. Although this extra power allows for a reduction in the size of the main boiler for new power plants, existing plants must be able to handle this additional power to implement a CaL-based solution for carbon capture.

The calculated penalties of the three simulated processes are in accordance with similar carbon capture simulation already published, ${ }^{[48]}$ and generally lower than other capture technologies, such as conventional amine absorption, with penalties of about $10 \% .{ }^{[48,49]}$ The combined CaL--CLC processes result in efficiencies that are 2.4--2.9\% higher than those of CaL. Such an improvement is due to the absence of both the ASU and purification step in the compression of the $\mathrm{CO}_{2}$ stream. The combined processes also require less fuel because the energy required to heat the reactants in the calciner is reduced with the absence of oxygen feed to the reactor. Notably, if higher flue gas recycle ratios are required to maintain fluidization conditions in the CaL--CLC cases, increased air infiltration requires a purification step in the $\mathrm{CO}_{2}$ compression section. This change occurs at a $\left(\mathrm{CO}_{2}+\mathrm{H}_{2} \mathrm{O}\right) / \mathrm{CH}_{4}$ ratio of around 1.5, and causes the efficiency difference between CaL and CaL--CLC to fall from $2.5-3 \%$ to about $1.5 \%$ (not shown).

As explained in the Introduction, the two CaL--CLC configurations require the transfer of energy released in the air reactor to the calciner and this is achieved by using the solids sensible heat. The required solids circulation rates are also shown in Table 3 . The 
oxidation of copper generates about $75 \%$ of the total heat from the carbon capture process, requiring relatively high circulation rates to transfer energy to the calciner. The simulations of both combined CaL--CLC processes result in solids flow rates an order of magnitude above that of CaL. The CaL--CLC dual loop does not require energy to heat the copper pellets because they are fed directly from the air reactor at a higher temperature; this explains the difference between the two configurations.

It should be noted that, in the presented results, the choice was made to maximize the efficiency of both CaL--CLC systems by transferring as much as possible of the energy released in the air reactor to the calciner, at the cost of solid circulation. Another approach could be to keep the solids circulation rate at a minimum by reducing the proportion of support material in the particles. This would then increase the fuel requirement in the calciner and the power production from the capture process, leading to an increase in the energy penalty, but also limit the solids circulation rate.

The $\mathrm{CaL}$ process also appears to have a higher $\mathrm{CO}_{2}$ intensity, as defined by Equation (3): ffr8

$$
\text { ff8 } \mathrm{CO}_{2} \text { intensity }=\frac{q_{\mathrm{CO}_{2} \text { tot }}}{P_{\text {net tot }}} \mathrm{ZS}(3)
$$

in which $q \mathrm{CO}_{2}$ tot is the total amount of $\mathrm{CO}_{2}$ remaining in the flue gas after the capture process $\left(\mathrm{kg} \mathrm{CO}_{2} /\right.$ in $\left.\mathrm{h}^{\mathrm{M}-1}\right)$ and $P_{\text {net tot }}$ is the total net power produced by both the base power plant and the capture process $\left(\mathrm{MW}_{\mathrm{e}}\right)$.

The difference in $\mathrm{CO}_{2}$ intensity is due to greater power output from the combined CaL--CLC processes. A slight difference between the two CaL--CLC configurations is observed because the dual-loop process captures more $\mathrm{CO}_{2}$ in the carbonator, which reduces the emissions level, while giving a similar power output, as shown in Table 3 .

The differences in solids flow rates should also impact the auxiliaries due to solid transfer between the reactors. In the pilot work mentioned the Introduction, this was achieved by using fluidized-bed loop seals, ${ }^{[32]}$ an air conveying line,${ }^{[34]}$ or a screw conveyor. ${ }^{[31]}$ Given 
the high solids circulation rates expected in the process, the design of a loop seal by using Basu's method $^{[50]}$ has been estimated. The results showed that the power duties required to operate the loop seals were negligible compared with the power consumed by the reactor fans. Consequently, the exact design of the loop seals and the power associated with their operation are not part of this work.

\section{Sensitivity analysis}

The effect of the carbonator temperature on the three process configurations can be seen in Table 4 . The $\mathrm{CaL}$ case reaches equilibrium conditions at $708^{\circ} \mathrm{C}$, whereas the $\mathrm{CaL}--$ CLC are limited to $701{ }^{\circ} \mathrm{C}$. This difference arises from different carbon capture levels in the carbonator required to reach the $60 \%$ global capture target in each configuration, resulting in different $\mathrm{CO}_{2}$ concentrations in the reactor. Indeed, the carbon capture process configuration modifies the calciner fuel consumption, which affects the carbon balance of the simulation. Operating the carbonator at a temperature closer to that of the calciner reduces the energy required to heat reactants, which reduces the fuel consumption. With a reduced methane feed rate, the flue gas flow rate is also reduced, and consequently, the power produced by the capture process drops.

The energy penalty is only slightly affected by this change. The power production efficiency associated with the capture process (not shown) decreases slightly due to the reduction of the power output, while giving very similar auxiliary power consumptions. However, the reduction of the proportion of low-efficiency power (from the capture process) in the overall process increases the overall efficiency, which balances the negative effect.

The solids flow rate increases slightly in the $\mathrm{CaL}$ case because it is required to capture more carbon in the carbonator to maintain the global capture level. The opposite trend is observed in the CLC loop of the CaL--CLC cases because the circulation of solids is mostly related to the energy balance in the calciner. 
To observe the effect of the calciner temperature independently from the air reactor temperature, both temperatures are varied to maintain a temperature difference of $50{ }^{\circ} \mathrm{C}$. The results of this analysis are summarized in Table 5. Decreasing the calciner temperature has a similar influence to that of an increase of the carbonator temperature, but with a stronger effect. It causes a reduction of the energy required to heat the solids transferred from the carbonator, but also the make-up stream, fuel feed, and flue gas recycling stream. The same interpretation can thus be applied here.

A minimum operating temperature of the calciner is reached when the gas composition in the reactor reaches the equilibrium $\mathrm{CO}_{2}$ concentration at that temperature. This temperature varies depending on the process: $863{ }^{\circ} \mathrm{C}$ for $\mathrm{CaL}, 867{ }^{\circ} \mathrm{C}$ for CaL--CLC single loop, and 868 ${ }^{\circ} \mathrm{C}$ for CaL--CLC dual loop. A difference is observed because a higher methane feed flow rate also produces more water, which dilutes the gas environment.

Table 6 presents the influence of the air reactor temperature on the overall process. Changes in energy production depend on the temperature difference between the calciner and the air reactor, and two different trends can be observed depending on the process configuration. In the CaL--CLC single-loop process, the copper content of the composite pellet is adjusted, along with the recycling rate to obtain a thermally neutral calciner and air reactor. With an increase in air reactor temperature, the copper fractional content becomes higher to maintain the same mass of circulating copper with a reduced global solids flow rate. The total mass of solids transferred from the carbonator to the calciner is thus higher at higher air reactor temperatures, which causes an increase in fuel consumption and energy losses through the process outlets.

The change in air reactor temperature in the CaL--CLC dual-loop case only affects the amount of support material circulating in the CLC loop. The amount of solids from the carbonator is not affected by this change and neither is the energy production in this case. Consequently, the only major changes in the simulation are the solids flow rate and the copper content of the solids. The covered range of temperature causes a modification of the solids 
circulation by an order of magnitude. The reason for such an important change is that $75 \%$ of the energy contained in the fuel is released in the air reactor and that it is transferred to the calciner through the solids sensible heat.

Table 7 provides a summary of the influence of $\mathrm{CaO}$ conversion on the overall process. At higher conversion, the amount of inert solids circulating in the process loops is reduced, which decreases the energy required in the calciner, leading to lower energy input and power output. The $\mathrm{CO}_{2}$ intensity of the processes at higher sorbent conversion increases due to the reduced power output.

The impact of the solids conversion on the energy penalty varies, depending on the process configuration. For both $\mathrm{CaL}$ and CaL--CLC single-loop processes, a decrease in the penalty is observed, although the efficiency of the power produced from the capture process decreases (not shown). This is due to the increase of the high-efficiency power proportion (from the base power plant) in the overall process, which balances the negative effect. The trend is reversed for the CaL--CLC dual-loop configuration. In this case, the overall process is less affected by changes on the $\mathrm{CaL}$ side and results in higher energy loss through the process outlets at high solids conversion. The balancing effect mentioned for the two other configurations is then not great enough here and the energy penalty is increased.

Increasing the targeted $\mathrm{CO}_{2}$ capture level causes greater requirements of sorbent and fuel to increase $\mathrm{CO}_{2}$ capture in the carbonator, as well as provide the energy for calcination and heating reactants in the calciner. Power production from the capture process becomes more efficient at a higher capture level. This is due to a higher proportion of energy being recovered from the carbonator, which does not contribute to energy loss, as opposed to material streams when they leave the process. However, the extra power obtained from the capture process is produced with a lower efficiency than that of the base power plant. At higher $\mathrm{CO}_{2}$ capture levels, the contribution to the overall power output of this low-efficiency part increases, which results in a reduction of the overall efficiency. 
Capture levels below $60 \%$ were also investigated with the goal of reaching the Canadian regulations of $420 \mathrm{~kg} \mathrm{CO}_{2} /$ in $\mathrm{MW}_{\mathrm{e}}{ }^{\mathrm{M}-1}$ (Table 8). This could be achieved with capture levels of 55.4, 53.1, and 52.9\% for the CaL, CaL--CLC single-loop, and CaL--CLC dual-loop processes, respectively.

Cases in which multiple operating parameters were changed are also simulated to provide a preliminary rough optimization of the different processes. The calciner temperature was set $20^{\circ} \mathrm{C}$ above the minimum found in the previous parametric study to operate above the equilibrium temperature. The carbonator was operated at the highest possible temperature and not lower than the base case temperature of $650{ }^{\circ} \mathrm{C}$. The air reactor in the CaL--CLC processes was fixed at $950{ }^{\circ} \mathrm{C}$. The $\mathrm{CO}_{2}$ capture level was reduced to achieve a carbon intensity of $420 \mathrm{~kg} \mathrm{CO}_{2} / \mathrm{in}_{\mathrm{MW}_{\mathrm{e}}}^{\mathrm{M}-1} \mathrm{~h}^{\mathrm{M}-1}$ or to maintain the carbonator temperature, whichever was reached first. The results of this analysis are presented in Table 9. Compared with the base case results, fuel consumption is reduced by about $15 \%$ in all cases, while the solids circulation rates are decreased by $11 \%$ for $\mathrm{CaL}$ and $30 \%$ for the two CaL--CLC configurations.

\section{Conclusions}

Process simulations were performed by using AspenONE for multiple carbon capture process configurations, including $\mathrm{CaL}$ and combined $\mathrm{CaL}$ and CLC.

The comparison of $\mathrm{CaL}$ and the combined CaL--CLC process showed that the use of the combined processes resulted in a more efficient process, with an energy penalty reduced by up to $40 \%$. However, such results were at the cost of greater solids circulation rates and process complexity; which would lead to an increase of the capital and operating costs of the process. The alternative CaL--CLC dual-loop configuration managed to reduce the solids mass flow rate by about 10 to $20 \%$ and produced less power, while maintaining a very similar energy efficiency. The solids circulation could also be reduced by considering a partial $\mathrm{CO}_{2}$ capture level because analysis showed that only lower capture levels were required to meet the current regulations in Canada. 
The influence of key process operating parameters was also investigated. The air reactor temperature had a strong influence on the mass of solids circulating in the process. Indeed, the temperature difference had a direct effect on the amount of energy transferred to the calciner per unit of solids mass. Results indicated that increasing the temperature difference between the air reactor and the calciner from 10 to $50{ }^{\circ} \mathrm{C}$ changed the solid circulation by an order of magnitude.

To assess the importance of reactor temperatures on both the process operation and sorbent performance degradation, reactor modeling could be implemented in the process simulation, but would also require extensive experimental data. This would also provide details on the hydrodynamics of the reactors and allow sizing and costing of the process unit operations.

\section{Computational Details}

\section{General}

The simulation of the carbon capture process and power generation was performed by using AspenONE unit operation blocks. In addition, the Aspen Workbook add-on for Microsoft Office Excel was used to control the simulations.

\section{Base power plant and flue gas properties}

The $\mathrm{CO}_{2}$ capture process was based on the flue gas of a supercritical pulverized coal power plant burning Illinois \#6 coal and generating $550 \mathrm{MW}_{\mathrm{e}}$ of net power (case 11 in Ref.). The flue gas was treated for $\mathrm{NO}_{x}$ with selective catalytic reduction and for $\mathrm{SO}_{x}$ with wet limestone forced oxidation scrubbing. Final flue gas conditions used in the simulations are listed in Table 10. The $\mathrm{SO}_{x}$ levels were reduced to below $20 \mathrm{ppm}$ in the flue gas desulfurization unit and its effect on the $\mathrm{CaO}$ sorbent was considered to be negligible in this study.

The steam cycle conditions and the efficiency of the power production are indicated in Table 11. 


\section{Capture process configurations}

$\mathrm{CaL}$ served herein as the basis of comparison. Calcium oxide based sorbents were circulated between the carbonator, where they reacted with $\mathrm{CO}_{2}$, and the calciner, where the sorbent was regenerated by the combustion of methane (Scheme 3). Methane was chosen herein instead of coal to compare the different processes on the same fuel basis. Previous work from various authors showed that the cycling of calcium oxide at high temperatures caused sintering, which degraded the sorbent structure and reduced its capture capacity. ${ }^{[10,11,13,14]}$ To maintain a sufficiently high conversion in the carbonator, deactivated sorbent had to be purged and fresh solids were added to the process.

The addition of copper to the circulated pellets required the addition of a third reactor, in which reduced copper would react with air to return to its oxidized state. Multiple sequencings of the reactors were possible.

The carbonation and oxidation reactions could be performed in the same reactor. ${ }^{[51]}$ The fixedbed experiments demonstrated that the oxidation of copper was feasible by using residual oxygen typically present in a combustion flue gas and at a temperature that also allowed carbonation to occur. However, the low quantity of oxygen present in the flue gas would not be sufficient to oxidize the calculated amount of copper circulating in the process and a dedicated air reactor was required.

To minimize the fuel consumption, a sequence of three reactors (carbonator $\rightarrow$ air reactor $\rightarrow$ calciner) could operate the air reactor at a higher temperature than that of the calciner. This would naturally transfer heat from the oxidation reaction to the calciner through the sensible heat of the solids. However, this configuration would cause the calcination of the calcium carbonate in the air reactor, leading to a lower net $\mathrm{CO}_{2}$ capture efficiency. The rate of this undesired decomposition could be controlled by increasing the pressure of this reactor, but it would complicate the overall process and calcination would always happen occur if the temperature were high enough. ${ }^{[52]}$

The choice was made to operate the calciner before the air reactor to avoid the loss of $\mathrm{CO}_{2}$ during the oxidation of copper (Scheme 4). To recover the heat from the air reactor in the calciner, a recycle loop was implemented between the air reactor and the calciner (dashed arrow on Scheme 4), as reported by Ozcan et al. $^{[48]}$ The former would operate at a higher temperature and the oxidized and 
calcined solids would be returned to the calciner to release sensible heat and contribute to the calcination of the sorbent from the carbonator.

Part of the calciner gas outlet was recycled to dilute the fuel feed stream before entering the reactor. It was also assumed that there was no leakage of gas between the air reactor and the calciner, as proven to be possible by Adánez et al. ${ }^{[53]}$

The CaL--CLC process presented in Scheme 44 circulated $\mathrm{CaO}$ C- $\mathrm{CuO}$ C- $\mathrm{Al}_{2} \mathrm{O}_{3}$ composite pellets between the three reactors. As such, the sintering of the sorbent was accelerated because calcium oxide was exposed to higher temperatures than those in the $\mathrm{CaL}$ process alone. As a consequence, a higher make-up flow would be required to maintain the desired carbonation reaction conversion level.

To avoid transfer of calcium oxide to the air reactor, a new process configuration was proposed (Scheme 5). This new configuration combined $\mathrm{CaL}$ and CLC in two separate loops, with the calciner as a crossing point between them. The $\mathrm{CaL}$ side of the process would work in the same manner as that shown in Scheme 33 , whereas the CLC side would circulate alumina-supported copper between the air reactor and the calciner, as in a typical CLC process shown in Scheme 11 .

Although offering benefits over the previous looping configuration, this process also brought the challenge of continuous solid--solid separation. The first solution would involve introducing differences in size and/or densities of the two particles during manufacturing. This would create different fluidization conditions for each particle and allow their classification during the operation of the reactor. Unit operations dedicated to this type of separation also already existed in the form of air classifiers. However, the high solid load and temperature were not the typical operating conditions of such units.

Another solution would involve indirect heat transfer for the calcination of the calcium carbonates. The calciner would consist of two distinct chambers and the solids would not be mixed. The use of cyclonic preheaters ${ }^{[54]}$ and integrated reactors ${ }^{[55]}$ could achieve such a process. The implementation of indirect heating for a CaL process was investigated by Reitz et al. ${ }^{[56]}$ in a $300 \mathrm{~kW}_{\text {th }}$ unit with an air-fired combustor coupled to the calciner. The use of indirect heating with CLC has not 
yet been demonstrated. In this simulation, it was assumed that either one of these options was implemented, that the solids remained in their own loop, and that the energy released by copper oxide reduction was fully used to heat and calcine the solids from the carbonator. Similarly to the singleloop configuration, no gas leakage between the air reactor and the calciner was assumed.

Each configuration of the capture process used a different solids composition (Table 12). In the $\mathrm{CaL}$ case, calcium oxide was pelletized with alumina as a support. The mass fraction of support was set to $10 \%$, based on the work of Manovic and Anthony. ${ }^{[39]}$ In the CaL--CLC single-loop process, copper oxide was added to the pellets. The proportion of copper was adjusted so that the energy produced by copper oxide reduction matched the energy required to calcine calcium carbonate in the calciner and maintain the temperature of the reactor. In the CaL--CLC dual-loop case, the CaL side circulated the same solids as in the CaL case, whereas the CLC loop contained alumina-supported copper oxide. The composition of the latter was again adjusted to have a neutral calciner heat duty.

In a CLC setup, pellets with a copper content above $15 \mathrm{wt} \%$ could lead to agglomeration and defluidization, depending on the operating temperature of the reactors. ${ }^{[43]}$ In the present case, the calculated copper content of the pellets was always below that limit. In addition, the works of GarcíaLario et al. ${ }^{[57]}$ and Abdul Rahman et al. ${ }^{[44]}$ showed that a higher copper content could be used if a different pellet manufacturing technique were used.

\section{Capture process}

There has been much work concerning the carbonation reaction ${ }^{[10-15,17,58]}$ and carbonator modeling ${ }^{[25,26,28,29]}$ because it is the core of the $\mathrm{CO}_{2}$ capture process. It is well known that both carbonation and calcination conditions (temperature, $\mathrm{CO}_{2}$, and water vapor concentrations) have an effect on the sorbent cyclic $\mathrm{CO}_{2}$ uptake capacity ${ }^{[12,58]}$ and different limestones show different resistance to sintering. ${ }^{[10]}$ A complete approach of the reactor simulation would require calcium oxide sorbent performance data on its capacity decay for every combination of reactor temperatures in the overall process to calculate an average conversion in the carbonator. Because such data was not available, the choice was made to set the conversion of the $\mathrm{CaO}$ in the carbonator. Set at $20 \%$ in the base case simulation, it was also varied between 10 and $40 \%$. Although the conversion of the sorbent 
observed during pilot operation ${ }^{[31,32,35]}$ was at the lower end of the investigated range, studies on CaL-CLC composite pellets showed that high conversion was achievable. ${ }^{[59,60]}$ In addition, sorbent conversion calculations based on TGA data showed that such conversions were possible. ${ }^{[4]}$

The carbonator was operated at $650^{\circ} \mathrm{C}$. Many thermogravimetric analysis (TGA) studies performed carbonation at this temperature ${ }^{[10,12,15,61-63]}$ because the reaction equilibrium favored the formation of calcium carbonate and allowed carbonation efficiencies above $90 \%$. Higher temperatures caused an increase in the equilibrium $\mathrm{CO}_{2}$ concentration [Eq. (4) in Ref.] and limited the carbon removal potential. However, if only partial carbon capture were considered, increasing the carbonator temperature could be beneficial to the process because it would reduce the fuel requirement in the calciner due to a lower temperature difference between reactors. In addition, it would also lead to accelerated reaction kinetics. Temperatures up to $700{ }^{\circ} \mathrm{C}$ were also tested in a sensitivity analysis. ffr 9 ff9 $\log P[\mathrm{~atm}]=7.079-\frac{38000}{4.574 * T[K]} \mathrm{ZS}(4)$

Most previous simulation work on the calcination reactor assumed complete calcination. ${ }^{[19-23]}$ Recent work on the calcination kinetics of carbonated particles ${ }^{[18]}$ and the development of calciner reactor models ${ }^{[24,27]}$ showed that calcination efficiencies above $95 \%$ could be obtained. Full calcination was assumed in all cases presented herein.

Natural gas was employed as the fuel for the calciner. The combustion of a solid fuel in a CLC scenario is possible,$^{[41,65,66]}$ but natural gas has been chosen to avoid the presence of sulfur and ash because both affect the sorbent performance negatively. ${ }^{[26,67-769]}$ The reduction of copper oxide by methane in composite CaL--CLC pellets has also been investigated by multiple authors and fast reaction kinetics were observed; ${ }^{[47,57,70]}$ this was also positive for the process because it favored the complete reduction of copper, and thus, the complete release of the required heat for calcination.

The calciner was operated at $900{ }^{\circ} \mathrm{C}$; a temperature sufficiently high enough to calcine calcium carbonate in an atmosphere containing $99 \% \mathrm{CO}_{2}$ at equilibrium. Although a lower temperature reduced the $\mathrm{CO}_{2}$ partial pressure at equilibrium, it also reduced the energy required to heat 
the solids transferred from the carbonator to the calciner. The extent of that fuel consumption reduction was investigated in a sensitivity analysis by lowering the calciner temperature to $863{ }^{\circ} \mathrm{C}$.

The simulation of the calciner also accounted for a heat loss of $1 \%$ (based on fuel energy input) and an air infiltration of $2 \%$ (based on flue gas flow rate). For CaL cases, oxygen was fed to the calciner in excess to reach a residual $\mathrm{O}_{2}$ concentration of $2.7 \%$ (dry basis) in the flue gas. ${ }^{[71]}$ Flue gas recycling was also implemented to dilute the oxygen feed concentration to $30 \% .{ }^{[72]}$ For CaL--CLC cases, the flue gas recycle loop aimed to dilute the methane feed to avoid possible carbon deposition or safety issues and provide appropriate fluidization conditions. A ratio of $\left(\mathrm{CO}_{2}+\mathrm{H}_{2} \mathrm{O}\right) / \mathrm{CH}_{4}$ of one was used in the base case. Because the hydrodynamics of the reactor were not modeled herein, the effects of higher ratios on the process were also discussed for the case in which higher gas velocities would be required.

The operation of the air reactor as a fluidized-bed reactor for $\mathrm{CaO} \mathrm{C}-\mathrm{CuO}$ composite pellets has not yet been explored experimentally. However, reactor modeling and process simulation were performed on a reforming process in a fixed-bed configuration. ${ }^{[46,73,74]}$ The oxidation reaction of copper in a $\mathrm{CaO} \mathrm{C}$ - $\mathrm{CuO}$ composite pellet has been studied in TGA experiments before, ${ }^{[42,59,60,70,75]}$ and literature on CLC using copper is also available.$^{[43,76-879]}$ All investigations showed that the use of copper as the oxygen carrier resulted in fast reaction kinetics, complete or very high conversion (above $90 \%$ ), and long reliability of the carrier performance over cycles number up to $70 .{ }^{[75]}$ For these reasons, complete and stable oxidation was assumed for the air reactor.

To transfer the heat of oxidation to the calciner, the air reactor had to operate at a higher temperature. Base case simulations set the air reactor temperature to $950{ }^{\circ} \mathrm{C}$ and values down to 910 ${ }^{\circ} \mathrm{C}$ were tested in a sensitivity analysis.

After calcination of the carbonate in the calciner, the produced gas was enriched in $\mathrm{CO}_{2}$, but also contained a significant amount of water vapor that needed to be condensed, along with residual oxygen and nitrogen from either the oxygen feed or infiltrated air. Depending on the dry basis purity of the $\mathrm{CO}_{2}$ stream, two different compression and purification processes were used. Following the recommendations of the "Carbon-Free Electricity by SEWGS: Advanced Materials, Reactor and 
Process Design" (CAESAR) project, ${ }^{[80]}$ the water vapor content was kept below $50 \mathrm{ppm}$ and the sum of non-condensable gases below $4 \%$. Depending on the application considered, additional oxygen removal might be required because the limit of 100 ppm for enhanced oil recovery was not met in the simulated cases.

In the $\mathrm{CaL}$ cases, purification was required due to excessive nitrogen content (about $7 \%$ on a dry basis). The cryogenic process proposed by Xu et al. ${ }^{[81]}$ was used. The flue gas was compressed to 2.1 MPa in a multistage compression before being cooled to $\mathrm{M}-35^{\circ} \mathrm{C} . \mathrm{CO}_{2}$ was condensed and separated from the other gases to meet the desired specifications. The cooling cycle operated with a coefficient of performance please define of 1.36 and $\mathrm{CO}_{2}$ recovery above $95 \%$ was achieved.

In the CaL--CLC cases, there was only a need for water vapor removal due to the low concentration of nitrogen and oxygen. This was performed by implementing a refrigeration and compression process by using the Joule--Thomson effect, as chosen by Abbas et al. ${ }^{[82,83]}$ The flue gas was compressed to about 4.0 MPa and throttled to 1.0 MPa in a Joule--Thomson valve. The resulting temperature drop caused the condensation of water vapor to meet the specification.

In both processes, the final product was compressed to 15.0 MPa. The compressors were simulated with an efficiency of $80 \%$ and pumps had an efficiency of $75 \%$.

The cryogenic distillation unit producing concentrated oxygen was not part of the presented simulation. The energy consumption of the ASU was determined based on the oxygen requirements of the calciner and available data on air separation. According to Darde et al., ${ }^{[84]}$ air separation plants required a specific energy of separation of around $200 \mathrm{~kW}_{\mathrm{e}} \mathrm{h}^{\mathrm{M}-1} \mathrm{t}_{2} /$ in ${ }^{\mathrm{M}-1}$. New designs, optimized for lower purity (95\%) oxygen production, could decrease this energy of separation to $160 \mathrm{~kW}_{\mathrm{e}} \mathrm{h}^{\mathrm{M}-1}$ $\mathrm{t}^{\mathrm{M}-1} \cdot \mathrm{O}_{2}$. However, the specific energy of separation does not consider compressor motor efficiencies, heat of regeneration of driers, and cooling system power consumption. Because such information was not provided, a value of $200 \mathrm{~kW}_{\mathrm{e}} \mathrm{h}^{\mathrm{M}-1} \mathrm{t}^{\mathrm{M}-1} \cdot \mathrm{O}_{2}$ was assumed herein. This value was similar to that of energy consumption used in previous works. ${ }^{[21,22]}$ The oxygen stream fed to the process had a purity of $95 \%$; the balance was nitrogen. 


\section{Steam cycle and power production}

High-quality heat was available in several locations within the capture process. The implemented heat integration is illustrated in Scheme 6 and uses a temperature approach of $20^{\circ} \mathrm{C}$. The recovered energy was then integrated in a dedicated supercritical steam cycle with reheating to produce power (Ref., case 11).

The boiler was replaced by four heat exchangers in series: $\mathrm{CO}_{2}$-enriched gas and the treated flue gas first generated vapor at $383{ }^{\circ} \mathrm{C}\left(Q_{\text {Boil 1 }}\right.$ and $\left.Q_{\text {Boil 1 }}\right)$. Half of the carbonator heat duty $\left(Q_{\text {Boil } 2}\right)$, followed by the calciner gas outlet $\left(Q_{\text {Boil } 3}\right)$, then heated the vapor to $593{ }^{\circ} \mathrm{C}$ at $24.2 \mathrm{MPa}$. The reheating of steam between the high- and intermediate-pressure turbines was performed by three heat exchangers. The solids purged, along with the other half of the carbonator duty and the carbonator gas outlet stream, contained enough energy to raise the temperature of the returning steam back to $593{ }^{\circ} \mathrm{C}$ at 4.5 MPa.

Before being compressed and purified, the $\mathrm{CO}_{2}$ stream was further cooled by using the boiled feed water $\left(Q_{\mathrm{BFW} 1}\right.$ and $\left.Q_{\mathrm{BFW} 2}\right)$ of the steam cycle. This allowed the reduction of steam extraction in the turbines and increased the power output. The heat exchanger nextwork (HEN) implementation was evaluated based on the proportion of energy transferred to the steam cycle, compared with the fuel energy value (HHV) fed to the calciner [Eq. (5)]: ffr10

$$
\text { ff10 } \eta_{\text {HEN }}=\frac{Q_{\text {SC }}}{q_{\text {fuel }} \mathrm{HHV}_{\text {fuel }}} \mathrm{ZS} \mathrm{(5)}
$$

in which $\eta_{\mathrm{HEN}}$ is the efficiency of the HEN, $Q_{\mathrm{SC}}$ is the rate of thermal energy transferred to the steam cycle $\left(\mathrm{MW}_{\text {th }}\right), q_{\text {fuel }}$ is the mass flow rate of fuel fed to the calciner $\left(\mathrm{kg} \mathrm{s}^{\mathrm{M}-1}\right)$, and $\mathrm{HHV}_{\text {fuel }}$ is the higher heating value of the fuel fed to the calciner $\left(\mathrm{MJ} \mathrm{k}^{\mathrm{M}-}\right)$.

The HEN had an efficiency of $78 \%$ for CaL, whereas the boiler efficiency of the base power plant was $88 \%$. The difference with the power plant could be attributed to an increased number of process outlet streams, which would increase the energy loss. For the same reason, the CaL--CLC configuration HEN efficiencies were slightly lower: $73 \%$ for the single loop and $76 \%$ for the CaL-- 
CLC dual loop. The dual-loop configuration resulted in greater efficiency due to the reduced energy required to heat solids to the reactor operating temperatures.

The auxiliaries contributing to this power consumption were composed of fans used to maintain the fluidized conditions in the reactors and overcome their $20 \mathrm{kPa}$ pressure drop; the ASU produced the required oxygen for the calciner operation ( $\mathrm{CaL}$ cases only) and the $\mathrm{CO}_{2}$ purification and compression system. In addition, an additional $5 \%$ power was deducted from the gross power output of the capture process to account for various auxiliaries not simulated herein, such as sorbent handling, fine particle removal, and cooling tower fans.

\section{Acknowledgements}

We are grateful to Dursun Can Ozcan for his insight and to cgs Carbon Management Canada /cgs for financial support.

lit1 pat J. C. Garcia Abanades, R. Murillo Villuenda, (Consejo Superior Investigacion, Spain), patn/ EP2305366A1, 2009/pat . changes

lit2 other International Energy Agency, Key World Energy Statistics, 2015, url http://www.iea.org/publications/freepublications/publication/key-world-energystatistics-2015.html /url, accessed 16 May 2016 /other please provide further information .

lit3 other International Energy Agency, $\mathrm{CO}_{2}$ Emissions from Fuel Combustion--Highlights, 2015, url http://www.iea.org/publications/freepublications/publication/co2-emissionsfrom-fuel-combustion-highlights-2015.html/url, accessed 16 May 2016 /other please provide further information .

lit4 other Government of Canada, Justice Laws Website, Reduction of Carbon Dioxide Emissions from Coal-fired Generation of Electricity Regulations, SOR/2012-167, 2012, url http://www.gazette.gc.ca/rp-pr/p2/2012/2012-09-12/html/sor-dors167eng.html\#REF28 /url, accessed April 2015 /other please provide further information . 
lit5 other Environmental Protection Agency, Federal Register, Standards of Performance for Greenhouse Gas Emissions From New Stationary Sources: Electric Utility Generating Units, 79 FR 1429, 2014, url https://www.federalregister.gov/articles/2014/01/08/201328668/standards-of-performance-for-greenhouse-gas-emissions-from-new-stationarysources-electric-utility/url, accessed April 2015 /other duplicate of ref. 4, please provide alternative of renumber .

lit6 jnl N. MacDowell, N. Florin, A. Buchard, J. Hallett, A. Galindo, G. Jackson, C. S. Adjiman, C. K. Williams, N. Shah, P. Fennell, Energy Environ. Sci. 2010, 3, 1645-1669 /jnl .

lit7 jnl L. M. Romeo, S. Espatolero, I. Bolea, Int. J. Greenhouse Gas Control 2008, 2, 563-$570 / \mathrm{jnl}$.

lit8 jnl J. Blamey, E. J. Anthony, J. Wang, P. S. Fennell, Prog. Energy Combust. Sci. 2010, 36, 260--279/jnl .

lit9 jnl M. E. Boot-Handford, J. C. Abanades, E. J. Anthony, M. J. Blunt, S. Brandani, N. MacDowell, J. R. Fernández, M.-C. Ferrari, R. Gross, J. P. Hallett, R. S. Haszeldine, P. Heptonstall, A. Lyngfelt, Z. Makuch, E. Mangano, R. T. J. Porter, M.

Pourkashanian, G. T. Rochelle, N. Shah, J. G. Yao, P. S. Fennell, Energy Environ. Sci. 2014, 7, 130--189/jnl .

lit10 jnl G. S. Grasa, J. C. Abanades, Ind. Eng. Chem. Res. 2006, 45, 8846--8851/jnl .

lit11 jnl J. C. Abanades, Chem. Eng. J. 2002, 90, 303--306/jnl .

lit12 jnl M. Broda, A. M. Kierzkowska, C. R. Müller, Environ. Sci. Technol. 2012, 46, 10849--10856/jnl .

lit13 jnl P. Sun, J. R. Grace, C. J. Lim, E. J. Anthony, AIChE J. 2007, 53, 2432--2442 /jnl . lit14 jnl V. Manovic, E. J. Anthony, Energy Fuels 2010, 24, 5790--5796/jnl . 
lit15 jnl W. Liu, B. Feng, Y. Wu, G. Wang, J. Barry, J. C. D. da Costa, Environ. Sci. Technol. 2010, 44, 3093--3097 /jnl .

lit16 other D. Y. Lu, R. W. Hughes, T. Reid, E. J. Anthony, Proceedings of the 20th International Conference on Fluidized Bed Combustion, 2010, pp. 569--575/other . lit17 jnl V. Manovic, E. J. Anthony, Environ. Sci. Technol. 2007, 41, 1420--1425 /jnl . lit18 jnl I. Martínez, G. Grasa, R. Murillo, B. Arias, J. C. Abanades, Energy Fuels 2012, 26, $1432--1440 / j n l$.

lit19 jnl D. P. Connell, D. A. Lewandowski, S. Ramkumar, N. Phalak, R. M. Statnick, L.S. Fan, Fuel 2013, 105, 383--396 /jnl .

lit20 jnl R. W. Hughes, D. Y. Lu, E. J. Anthony, A. Macchi, Fuel Process. Technol. 2005, $86,1523--1531 / \mathrm{jnl}$.

lit21 jnl L. M. Romeo, J. C. Abanades, J. M. Escosa, J. Paño, A. Giménez, A. SánchezBiezma, J. C. Ballesteros, Energy Convers. Manage. 2008, 49, 2809--2814/jnl . lit22 jnl W. Wang, S. Ramkumar, L.-S. Fan, Fuel 2013, 104, 561--574 /jnl . lit23 jnl W. Wang, S. Ramkumar, D. Wong, L.-S. Fan, Fuel 2012, 92, 94--106 /jn1 . lit24 jnl I. Martínez, G. Grasa, R. Murillo, B. Arias, J. C. Abanades, Chem. Eng. J. 2013, 215--216, 174--181/jnl .

lit25 jnl M. Alonso, N. Rodríguez, G. Grasa, J. C. Abanades, Chem. Eng. Sci. 2009, 64, $883--891 / j n 1$.

lit26 jnl M. C. Romano, Chem. Eng. Sci. 2012, 69, 257--269 /jnl .

lit27 jnl J. Ylätalo, J. Parkkinen, J. Ritvanen, T. Tynjälä, T. Hyppänen, Fuel 2013, 113, 770-779 /jnl .

lit28 jnl J. Ylätalo, J. Ritvanen, T. Tynjälä, T. Hyppänen, Fuel 2014, 115, 329--337 /jnl . 
lit29 jnl J. Ylätalo, J. Ritvanen, B. Arias, T. Tynjälä, T. Hyppänen, Int. J. Greenh. Gas Control 2012, 9, 130--135/jnl .

lit30 jnl A. Mackenzie, D. L. Granatstein, E. J. Anthony, J. C. Abanades, Energy Fuels 2007, 21, 920--926/jnl .

lit31 jnl J. Ströhle, M. Junk, J. Kremer, A. Galloy, B. Epple, Fuel 2014, 127, 13--22 /jn1 .

lit32 jnl B. Arias, M. E. Diego, J. C. Abanades, M. Lorenzo, L. Diaz, D. Martínez, J.

Alvarez, A. Sánchez-Biezma, Int. J. Greenhouse Gas Control 2013, 18, 237--245 /jnl .

lit33 jnl C. Hawthorne, H. Dieter, A. Bidwe, A. Schuster, G. Scheffknecht, S. Unterberger, M. Käß, Energy Procedia 2011, 4, 441--448 /jnl .

lit34 jnl D. Y. Lu, R. W. Hughes, E. J. Anthony, Fuel Process. Technol. 2008, 89, 1386-$1395 /$ jnl .

lit35 jnl H. Dieter, A. R. Bidwe, G. Varela-Duelli, A. Charitos, C. Hawthorne, G.

Scheffknecht, Fuel 2014, 127, 23--37 /jnl .

lit36 jnl R. T. Symonds, D. Y. Lu, V. Manovic, E. J. Anthony, Ind. Eng. Chem. Res. 2012, 51, 7177--7184/jnl .

lit37 jnl Y. Wu, V. Manovic, I. He, E. J. Anthony, Fuel 2012, 96, 454--461 /jnl . lit38 jnl V. Manovic, E. J. Anthony, Environ. Sci. Technol. 2009, 43, 7117--7122 /jnl . lit39 jnl V. Manovic, E. J. Anthony, Energy Fuels 2009, 23, 4797--4804 /jnl . lit40 jnl Z. Li, N. Cai, Y. Huang, H. Han, Energy Fuels 2005, 19, 1447--1452 /jnl . lit41 jnl J. Adanez, A. Abad, F. Garcia-Labiano, P. Gayan, L. F. de Diego, Prog. Energy Combust. Sci. 2012, 38, 215--282/jnl .

lit42 jnl V. Manovic, E. J. Anthony, Energy Fuels 2011, 25, 4846--4853 /jnl .

lit43 jnl L. F. De Diego, P. Gayan, F. Garcia-Labiano, J. Celaya, A. Abad, J. Adanez, Energy Fuels 2005, 19, 1850--1856/jnl . 
lit44 jnl R. Abdul Rahman, M. Poupak, D. Y. Lu, E. J. Anthony, A. Macchi, Energy Fuels 2015, 29, 3808--3819/jnl .

lit45 jnl J. C. Abanades, R. Murillo, J. R. Fernandez, G. Grasa, I. Martínez, Environ. Sci. Technol. 2010, 44, 6901--6904/jnl .

lit46 jnl J. R. Fernández, J. C. Abanades, R. Murillo, G. Grasa, Int. J. Greenhouse Gas Control 2012, 6, 126--141/jnl .

lit47 jnl C. Qin, B. Feng, J. Yin, J. Ran, L. Zhang, V. Manovic, Chem. Eng. J. 2015, 262, $665--675 / j n l$.

lit48 jnl D. C. Ozcan, A. Macchi, D. Lu, A. M. Kierzkowska, H. Ahn, C. R. Müller, S. Brandani, Int. J. Greenhouse Gas Control 2015, 43, 198--212 /jnl .

lit49 other National Energy Technology Laboratory NETL, Department of Energy (DOE), Cost and Performance Baseline for Fossil Energy Plants----Vol. 1: Bituminous Coal and Natural Gas to Electricity, DOE/NETL-2010/1397, Revision 2a 2013, url https://www.netl.doe.gov/File\%20Library/Research/Energy\%20Analysis/OE/BitBase ?_FinRep ?_Rev2a-3 ?_20130919 ?_1.pdf/url /other .

lit50 bk -P. Basu, Circulating Fluidized Bed Boilers : Design, Operation and Maintenance, $1^{\text {st }}$ ed., Springer, New York, 2015 /jnl .

lit51 jnl F. N. Ridha, D. Lu, A. Macchi, R. W. Hughes, Fuel 2015, 153, 202--209 /jnl . lit52 jnl J. W. Butler, C. J. Lim, J. R. Grace, Chem. Eng. Res. Des. 2011, 89, 1794--1804 /jnl .

lit53 jnl J. Adánez, C. Dueso, L. F. de Diego, F. García-Labiano, P. Gayán, A. Abad, F. Garcia-Labiano, P. Gayan, Energy Fuels 2009, 23, 130--142 /jnl .

lit54 jnl A. Martínez, Y. Lara, P. Lisbona, L. M. Romeo, Environ. Sci. Technol. 2013, 47, 11335--11341/jnl . 
lit55 jnl J. C. Abanades, E. J. Anthony, J. Wang, J. E. Oakey, Environ. Sci. Technol. 2005, 39, 2861--2866/jnl .

lit56 other M. Reitz, M. Junk, J. Ströhle, B. Epple, Energy Procedia 2014, 63,2170--2177 /other please check reference: it seems to have been published in Energy Procedia 2014, 63,2170--2177. if not: what is the page number/the name of the proceedings spelled out? .

lit57 jnl A. L. García-Lario, I. Martínez, R. Murillo, G. Grasa, J. R. Fernández, J. C. Abanades, Ind. Eng. Chem. Res. 2013, 52, 1481--1490/jnl .

lit58 jnl S. Champagne, D. Y. Lu, A. MacChi, R. T. Symonds, E. J. Anthony, Ind. Eng. Chem. Res. 2013, 52, 2241--2246/jnl .

lit59 jnl A. M. Kierzkowska, C. R. Müller, Energy Environ. Sci. 2012, 5, 6061--6065 /jnl . lit60 jnl C. Qin, J. Yin, C. Luo, H. An, W. Liu, B. Feng, Chem. Eng. J. 2013, 228, 75--86 /jnl .

lit61 jnl Z. Li, N. Cai, Y. Huang, Ind. Eng. Chem. Res. 2006, 45, 1911--1917 /jnl .

lit62 jnl N. H. Florin, J. Blamey, P. S. Fennell, Energy Fuels 2010, 24, 4598--4604 /jnl . lit63 jnl M. Broda, C. R. Müller, Fuel 2014, 127, 94--100 /jnl . lit64 jnl E. H. Baker, J. Chem. Soc. 1962, 464--470 /jnl . lit65 jnl Q. Imtiaz, D. Hosseini, C. R. Müller, Energy Technol. 2013, 1, 633--647 /jnl . lit66 jnl I. Adánez-Rubio, A. Abad, P. Gayán, L. F. de Diego, F. García-Labiano, J. Adánez, Fuel 2012, 102, 634--645 /jnl .

lit67 jnl G. S. Grasa, M. Alonso, J. C. Abanades, Ind. Eng. Chem. Res. 2008, 47, 1630-$1635 / \mathrm{jnl}$.

lit68 jnl C. Luo, Y. Zheng, J. Guo, B. Feng, Fuel 2014, 127, 124--130 /jnl . lit69 jnl M. E. Diego, B. Arias, M. Alonso, J. C. Abanades, Fuel 2013, 109, 184--190 /jnl . 
lit70 jnl V. Manovic, E. J. Anthony, Environ. Sci. Technol. 2011, 45, 10750--10756/jnl .

lit71 other National Energy Technology Laboratory NETL, Department of Energy (DOE), Quality Guidelines for Energy Systems Studies - Process Modeling Deisgn Parameters, DOE/NETL-341/051314, 2014,

http://www.netl.doe.gov/File\%20Library/Research/Energy\%20Analysis/Publications/Q GESS ProcessModDesignParameters Public Rev2 20140513.pdf, accessed April 2015 /other please complete following ref. 50 as example .

lit72 other Alstom Power Inc., PPL Report No. PPL-03-CT-09, 2003, url https://www.netl.doe.gov/File Library/Research/Coal/ewr/co2/5286-Alstom-CLCPrototype.pdf /url /other .

lit73 jnl J. R. Fernandez, J. C. Abanades, R. Murillo, Chem. Eng. Sci. 2012, 84, 1--11/jn1 . lit74 jnl J. R. Fernandez, J. C. Abanades, G. Grasa, Chem. Eng. Sci. 2012, 84, 12--20 /jnl . lit75 jnl C. Qin, J. Yin, W. Liu, H. An, B. Feng, Ind. Eng. Chem. Res. 2012, 51, 12274-$12281 / \mathrm{jnl}$.

lit76 jnl C. R. Forero, P. Gayán, F. García-Labiano, L. F. de Diego, A. Abad, J. Adánez, Int. J. Greenhouse Gas Control 2011, 5, 659--667 /jnl .

lit77 jnl J. Adanez, P. Gayan, J. Celaya, L. F. de Diego, F. Garcia-Labiano, A. Abad, Ind. Eng. Chem. Res. 2006, 45, 6075--6080/jnl .

lit78 jnl Q. Imtiaz, A. M. Kierzkowska, C. R. Müller, ChemSusChem 2012, 5, 1610--1618 /jnl .

lit79 jnl Q. Imtiaz, A. M. Kierzkowska, M. Broda, C. R. Müller, Environ. Sci. Technol. 2012, 46, 3561--3566/jnl .

lit80 other CAESAR Project, Deliverable 4.9, 2011, http://caesar.ecn.nl/fileadmin/caesar/user/documents/D 4.9 best practice guide.p df, Accessed April 2015 /other . 
lit82 jnl G. Xu, L. Li, Y. Yang, L. Tian, T. Liu, K. Zhang, Energy 2012, 42, 522--529 /jnl .

lit83 jnl Z. Abbas, T. Mezher, M. R. M. Abu-Zahra, Int. J. Greenhouse Gas Control 2013, 16, 324--334/jnl .

lit84 jnl Z. Abbas, T. Mezher, M. R. M. Abu-Zahra, Int. J. Greenhouse Gas Control 2013, 16, 335--341/jnl .

lit85 jnl A. Darde, R. Prabhakar, J.-P. Tranier, N. Perrin, Energy Procedia 2009, 1, 527--534 /jnl .

Received: January 14, 2016

Revised: February 24, 2016

Published online:

Scheme 1 General representation of a CLC process.

Scheme 2 General representation of a combined CaL--CLC process.

Scheme 3 General representation of the CaL process.

Scheme 4 General representation of the combined CaL--CLC single-loop process.

Scheme 5 General representationof the combined CaL--CLC dual-loop process.

Scheme 6 Heat exchanger network (HEN) for CaL--CLC single-loop process.

Table 1 Base case simulation parameters.

\begin{tabular}{|l|c|}
\hline Parameter & Value \\
\hline carbonator temperature $\left[{ }^{\circ} \mathrm{C}\right]$ & 650 \\
\hline calciner temperature $\left[{ }^{\circ} \mathrm{C}\right]$ & 900 \\
\hline air reactor temperature $\left[{ }^{\circ} \mathrm{C}\right]$ & 950 \\
\hline calcium oxide conversion $[\%]$ & 20 \\
\hline
\end{tabular}




\begin{tabular}{|l|c|}
\hline make-up ratio $\left(F_{0} / F \mathrm{CO}_{2} /\right.$ in $)$ & 0.1 \\
\hline global capture level $[\%]$ & 60 \\
\hline reactor pressure drop $[\mathrm{kPa}]$ & 20 \\
\hline
\end{tabular}

Table 2 Principal results for the base case. ${ }^{[\mathrm{a}]}$

\begin{tabular}{|c|c|c|c|}
\hline \multirow[t]{2}{*}{ Parameter } & \multirow[t]{2}{*}{$\mathrm{CaL}$} & \multicolumn{2}{|c|}{ CaL--CLC } \\
\hline & & single loop & dual loop \\
\hline thermal input (HHV $\left.\left[\mathrm{MW}_{\text {th }}\right]\right)$ & 716.5 & 604.1 & 573.9 \\
\hline extra gross power $\left[\mathrm{MW}_{\mathrm{e}}\right]$ & 256.2 & 202.1 & 199.7 \\
\hline ASU consumption $\left[\mathrm{MW}_{\mathrm{e}}\right]$ & 38.1 & -- & -- \\
\hline process fans $\left[\mathrm{MW}_{\mathrm{e}}\right]$ & 24.3 & 24.9 & 24.6 \\
\hline $\mathrm{CPU}\left[\mathrm{MW}_{\mathrm{e}}\right]$ & 78.1 & 49.3 & 48.7 \\
\hline process auxiliaries $\left[\mathrm{MW}_{\mathrm{e}}\right]$ & 12.8 & 10.1 & 10.0 \\
\hline extra net power $\left[\mathrm{MW}_{\mathrm{e}}\right]$ & 102.9 & 117.9 & 116.5 \\
\hline global net power $\left[\mathrm{MW}_{\mathrm{e}}\right]$ & 652.9 & 667.9 & 666.5 \\
\hline global net efficiency [HHV \%] & 30.86 & 33.33 & 33.77 \\
\hline energy penalty [HHV \%] & 8.44 & 5.97 & 5.53 \\
\hline
\end{tabular}

[a] $\mathrm{HHV}=$ higher heat value, $\mathrm{CPU}=$ compression and purification unit.

Table 3 Further results for the base case. 
CaL--CLC

single loop dual loop

\begin{tabular}{lccc}
\hline solids flow rate $\left[\mathrm{kg} \mathrm{s}^{\mathrm{M}-1}\right]$ & 476 & 7316 & 5797 \\
$\mathrm{Cu}$ content $[\mathrm{wt} \mathrm{\%}]$ & -- & 3.8 & 5.0 \\
$\mathrm{CO}_{2}$ intensity $\left[\mathrm{kg} \mathrm{CO}_{2} /{\left.\mathrm{in} \mathrm{MWh}^{\mathrm{M}-1}\right]}^{375}\right.$ & 355 & 353 \\
\hline
\end{tabular}

Table 4 Parameter analysis results----Impact of carbonator temperature (calciner temperature $=900{ }^{\circ} \mathrm{C}$; air reactor temperature $\left.=950{ }^{\circ} \mathrm{C}\right) . \mathrm{w}=3$

Parameter Configuration Carbonator

\section{$T=650{ }^{\circ} \mathrm{C} \quad T=675{ }^{\circ} \mathrm{C} \quad T=700{ }^{\circ} \mathrm{C}$ \\ $T=708$}

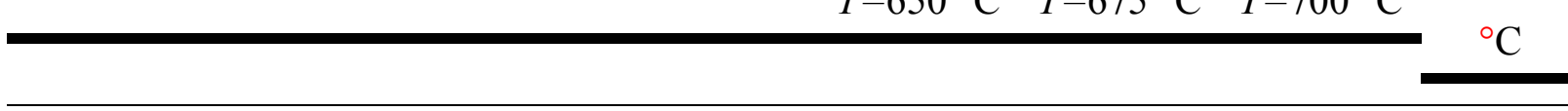

thermal power

input $\left[\mathrm{MW}_{\mathrm{th}}\right]$

$\mathrm{CaL}$

716.5

698.3

679.9

673.9

CaL--CLC single loop

$604.1 \quad 589.5 \quad 574.6$

CaL--CLC dual loop

$573.9 \quad 559.4 \quad 544.6$

extra net power output $\left[\mathrm{MW}_{\mathrm{e}}\right]$

$\mathrm{CaL}$

102.9

97.5

92.0

90.2

CaL--CLC single loop

117.9

112.7

107.2

CaL--CLC dual loop

$\begin{array}{lll}116.5 & 111.2 & 105.9\end{array}$

penalty

$\mathrm{CaL}$

8.44

8.44

8.43

8.42 
[HHV\%]

CaL--CLC single loop

CaL--CLC dual loop

solids flow rate

$\left[\mathrm{kg} \mathrm{s}^{\mathrm{M}-1}\right]$

$\mathrm{CaL}$
CaL--CLC single loop

CaL--CLC dual loop $\mid \begin{aligned} & \mathrm{CaL} \\ & \text { side }\end{aligned}$

CLC

side

5.97

5.53

5.55

5.56

476

478

480

481

7316

7139

6959

463

465

467

6.01

(

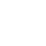


$\left[\mathrm{MW}_{\mathrm{th}}\right]$

CaL--CLC single loop

$\begin{array}{lll}578.8 & 588.7 & 604.1\end{array}$

CaL--CLC dual loop

$549.9 \quad 558.9 \quad 573.9$

extra net power output

$\left[\mathrm{MW}_{\mathrm{e}}\right]$

$\mathrm{CaL}$

$89.7 \quad 95.7$

102.9

CaL--CLC single loop

$\begin{array}{lll}108.8 & 112.4 & 117.9\end{array}$

CaL--CLC dual loop

$107.8 \quad 111.0 \quad 116.5$

penalty [HHV\%]

$\mathrm{CaL}$

8.42

8.43

8.44

CaL--CLC single loop

$6.00 \quad 5.98$

5.97

CaL--CLC dual loop

$5.56 \quad 5.55$

5.53

solids flow rate $\left[\mathrm{kg} \mathrm{s}^{\mathrm{M}-1}\right] \quad \mathrm{CaL}$

481

479

476

CaL--CLC single loop

7086

7177

7316

$\mathrm{CaL}$

CaL--CLC dual loop

side

467

465

463

CLC

$\begin{array}{llll} & 5191 & 5245 & 5334\end{array}$

$\mathrm{CO}_{2}$ intensity $\left[\mathrm{kg} \mathrm{CO}_{2} /\right.$ in

$\mathrm{MW}_{\mathrm{e}}^{\mathrm{M}-1} \mathrm{~h}^{\mathrm{M}-1}$ ]

$\mathrm{CaL}$

378

377

375

CaL--CLC single loop

357

356

355

CaL--CLC dual loop

355

354

353 
Table 6 Parameter analysis results----Impact of air reactor temperature (carbonator temperature $=650{ }^{\circ} \mathrm{C}$; calciner temperature $\left.=900{ }^{\circ} \mathrm{C}\right) . \mathrm{w}=3$

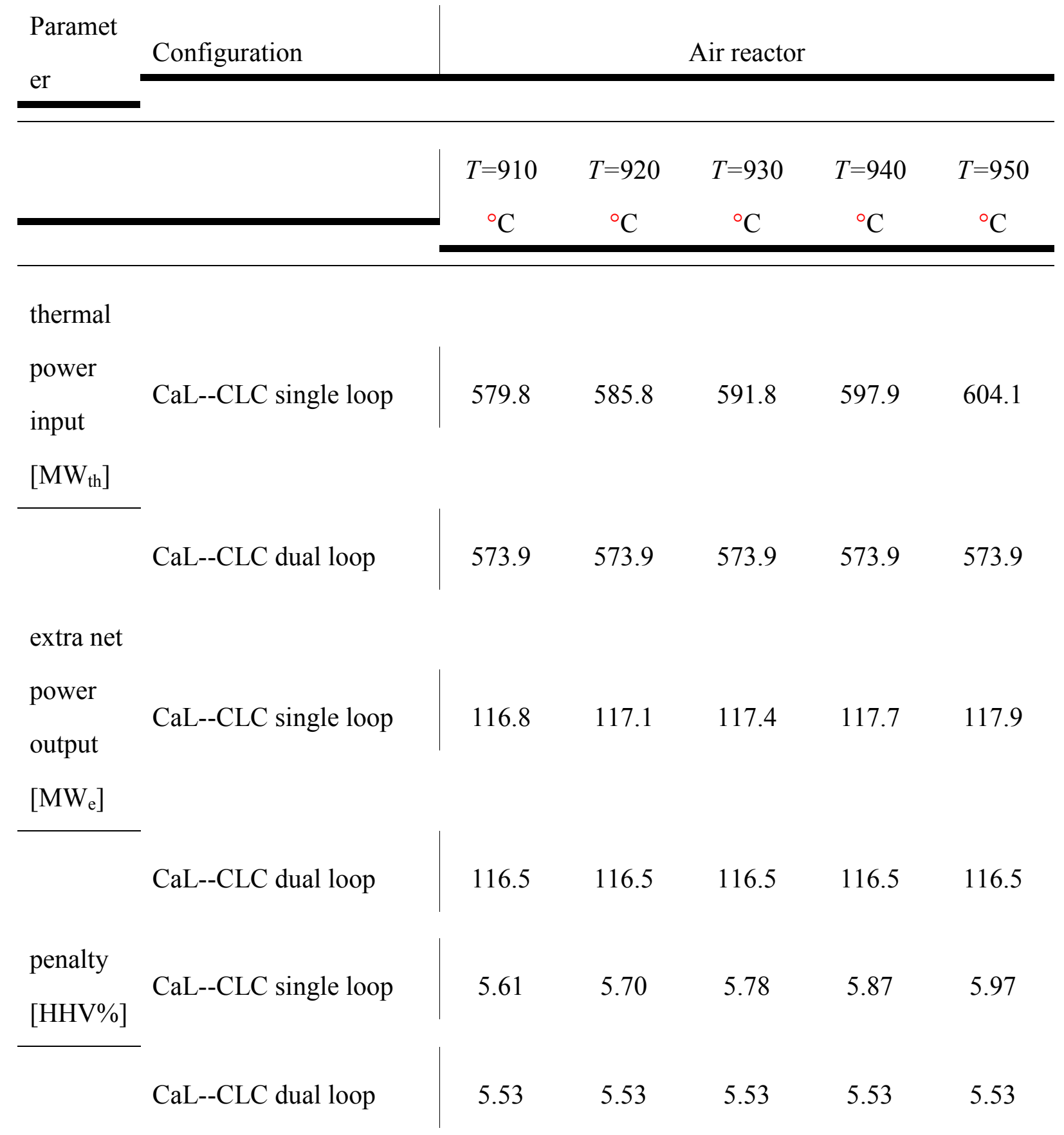

solids

flow rate $\left[\mathrm{kg} \mathrm{s}^{\mathrm{M}-}\right.$ CaL--CLC single loop 34928 17667 11914 9040 7316 $\left.{ }^{1}\right]$ 


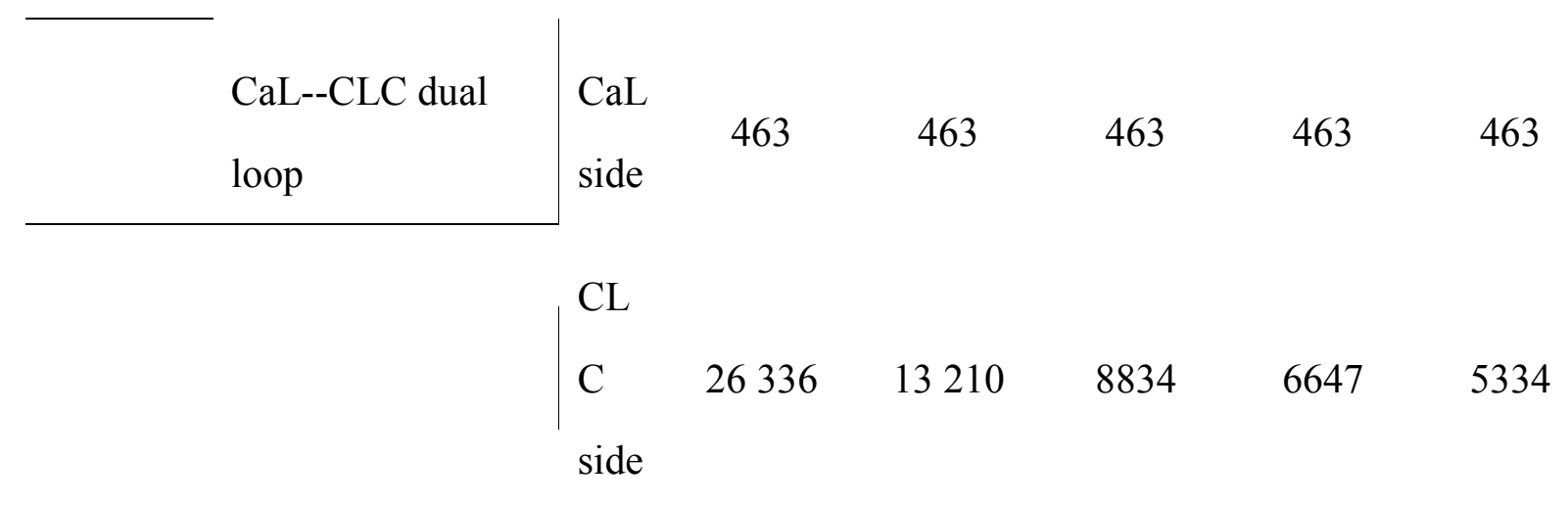

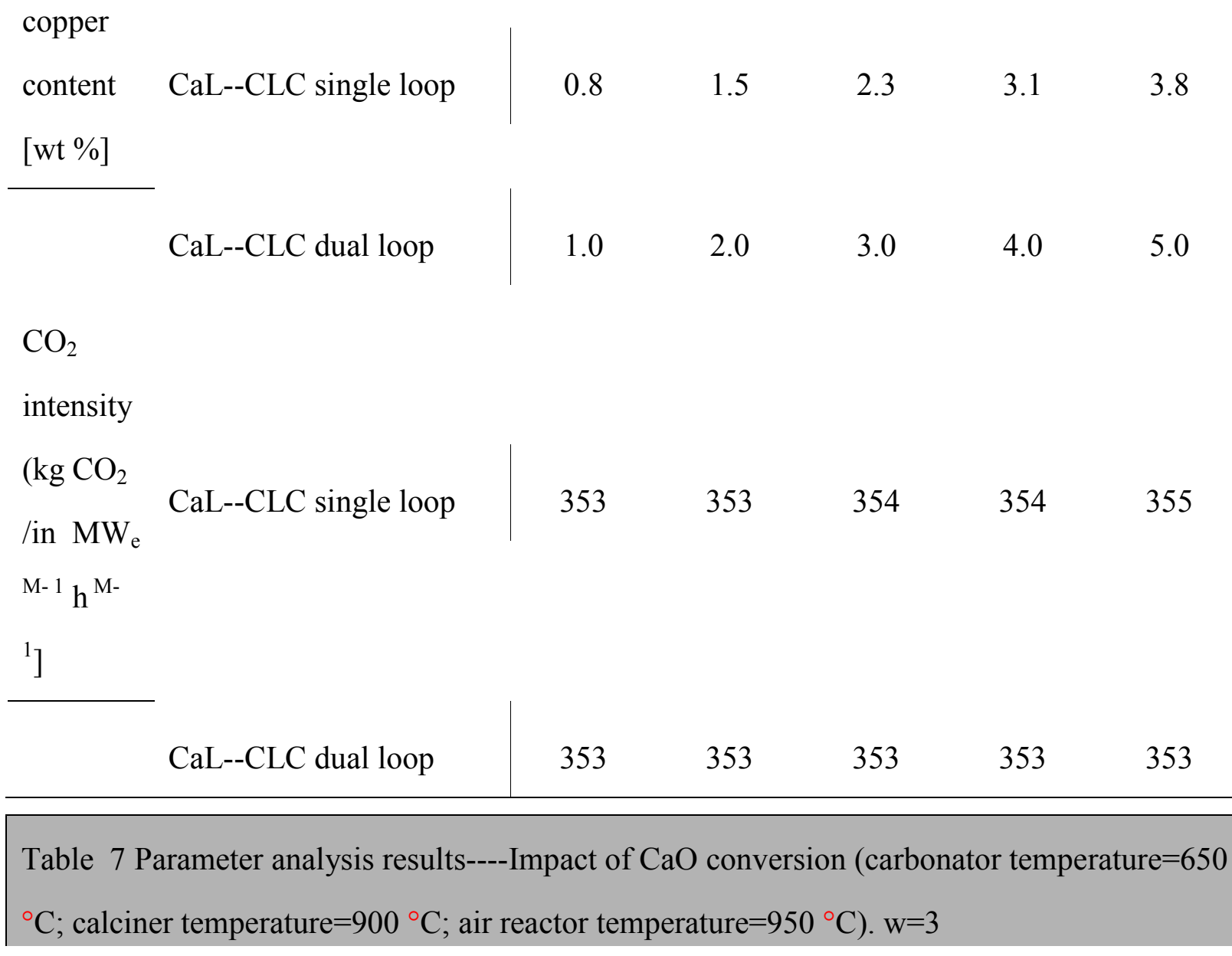

\begin{tabular}{|c|c|c|c|c|c|}
\hline \multirow[t]{2}{*}{ Parameter } & \multirow[t]{2}{*}{ Configuration } & \multicolumn{4}{|c|}{$\mathrm{CaO}$ conversion $[\%]$} \\
\hline & & 10 & 20 & 30 & 40 \\
\hline thermal power input $\left[\mathrm{MW}_{\text {th }}\right]$ & $\mathrm{CaL}$ & 850.2 & 716.5 & 666.7 & 641.5 \\
\hline & CaL--CLC single loop & 740.9 & 604.1 & 555.4 & 530.4 \\
\hline
\end{tabular}




\begin{tabular}{|c|c|c|c|c|c|}
\hline $\begin{array}{l}\text { extra net power output } \\
{\left[\mathrm{MW}_{\mathrm{e}}\right]}\end{array}$ & $\mathrm{CaL}$ & 143.4 & 102.9 & 88.1 & 80.6 \\
\hline & CaL--CLC single loop & 159.1 & 117.9 & 103.3 & 95.8 \\
\hline & CaL--CLC dual loop & 157.5 & 116.5 & 102.0 & 94.5 \\
\hline \multirow[t]{3}{*}{ penalty [HHV\%] } & $\mathrm{CaL}$ & 8.48 & 8.44 & 8.42 & 8.40 \\
\hline & CaL--CLC single loop & 6.17 & 5.97 & 5.88 & 5.84 \\
\hline & CaL--CLC dual loop & 5.39 & 5.53 & 5.58 & 5.61 \\
\hline \multirow[t]{2}{*}{ solids flow rate $\left[\mathrm{kg} \mathrm{s}^{\mathrm{M}-1}\right]$} & $\mathrm{CaL}$ & 853 & 476 & 341 & 272 \\
\hline & CaL--CLC single loop & 8973 & 7316 & 6726 & 6423 \\
\hline
\end{tabular}

\begin{tabular}{|c|c|c|c|c|c|c|}
\hline & CaL--CLC dual loop & $\begin{array}{l}\mathrm{CaL} \\
\text { side }\end{array}$ & 834 & 463 & 332 & 265 \\
\hline \multirow{4}{*}{$\begin{array}{l}\mathrm{CO}_{2} \text { intensity }\left[\mathrm{kg} \mathrm{CO}_{2} \text { /in }\right. \\
\left.\mathrm{MW}_{\mathrm{e}}^{\mathrm{M}-1} \mathrm{~h}^{\mathrm{M}-1}\right]\end{array}$} & & $\begin{array}{l}\text { CLC } \\
\text { side }\end{array}$ & 6387 & 5334 & 4964 & 4775 \\
\hline & $\mathrm{CaL}$ & & 371 & 375 & 379 & 380 \\
\hline & \multicolumn{2}{|l|}{ CaL--CLC single loop } & 348 & 355 & 358 & 359 \\
\hline & \multicolumn{2}{|l|}{ CaL--CLC dual loop } & 343 & 353 & 356 & 358 \\
\hline $\begin{array}{l}\text { Table } 8 \text { Parameter analysi } \\
\text { temperature }=650{ }^{\circ} \mathrm{C} \text {; calci }\end{array}$ & $\begin{array}{l}\text { Ilts----Impact of } \mathrm{CO}_{2} \mathrm{C} \\
\text { mperature }=900{ }^{\circ} \mathrm{C} \text {; ai }\end{array}$ & reacto & el (carb & onator & & \\
\hline
\end{tabular}




\begin{tabular}{|c|c|c|c|c|c|c|}
\hline \multirow{2}{*}{$\begin{array}{l}\text { Paramet } \\
\text { er }\end{array}$} & \multirow[t]{2}{*}{ Configuration } & \multicolumn{4}{|c|}{ Capture [\%] } & \multirow{2}{*}{$\begin{array}{c}\mathrm{CO}_{2} \\
\text { intensity } \\
(420 \mathrm{~kg} \\
\mathrm{CO}_{2} / \mathrm{in} \\
\mathrm{MW}_{\mathrm{e}}^{\mathrm{M}-1} \\
\left.\mathrm{~h}^{\mathrm{M}-1}\right]\end{array}$} \\
\hline & & 60 & 70 & 80 & 90 & \\
\hline \multirow[t]{2}{*}{$\begin{array}{l}\text { thermal } \\
\text { power } \\
\text { input } \\
{\left[\mathrm{MW}_{\text {th }}\right]}\end{array}$} & \multirow[b]{2}{*}{$\begin{array}{l}\text { CaL--CLC } \\
\text { single loop }\end{array}$} & 716.5 & 872.4 & 1044.7 & 1233.4 & 648.5 \\
\hline & & 604.1 & 732.0 & 870.1 & 1019.7 & 521.6 \\
\hline \multirow{4}{*}{$\begin{array}{l}\text { extra } \\
\text { net } \\
\text { power } \\
\text { output } \\
{\left[\mathrm{MW}_{\mathrm{e}}\right]}\end{array}$} & $\begin{array}{l}\text { CaL--CLC dual } \\
\text { loop }\end{array}$ & 573.9 & 693.1 & 821.3 & 959.4 & 493.9 \\
\hline & $\mathrm{CaL}$ & 102.9 & 136.3 & 173.2 & 213.6 & 88.3 \\
\hline & $\begin{array}{l}\text { CaL--CLC } \\
\text { single loop }\end{array}$ & 117.9 & 153.4 & 191.6 & 233.0 & 95.2 \\
\hline & $\begin{array}{l}\text { CaL--CLC dual } \\
\text { loop }\end{array}$ & 116.5 & 151.2 & 188.5 & 228.8 & 93.2 \\
\hline
\end{tabular}


penalty

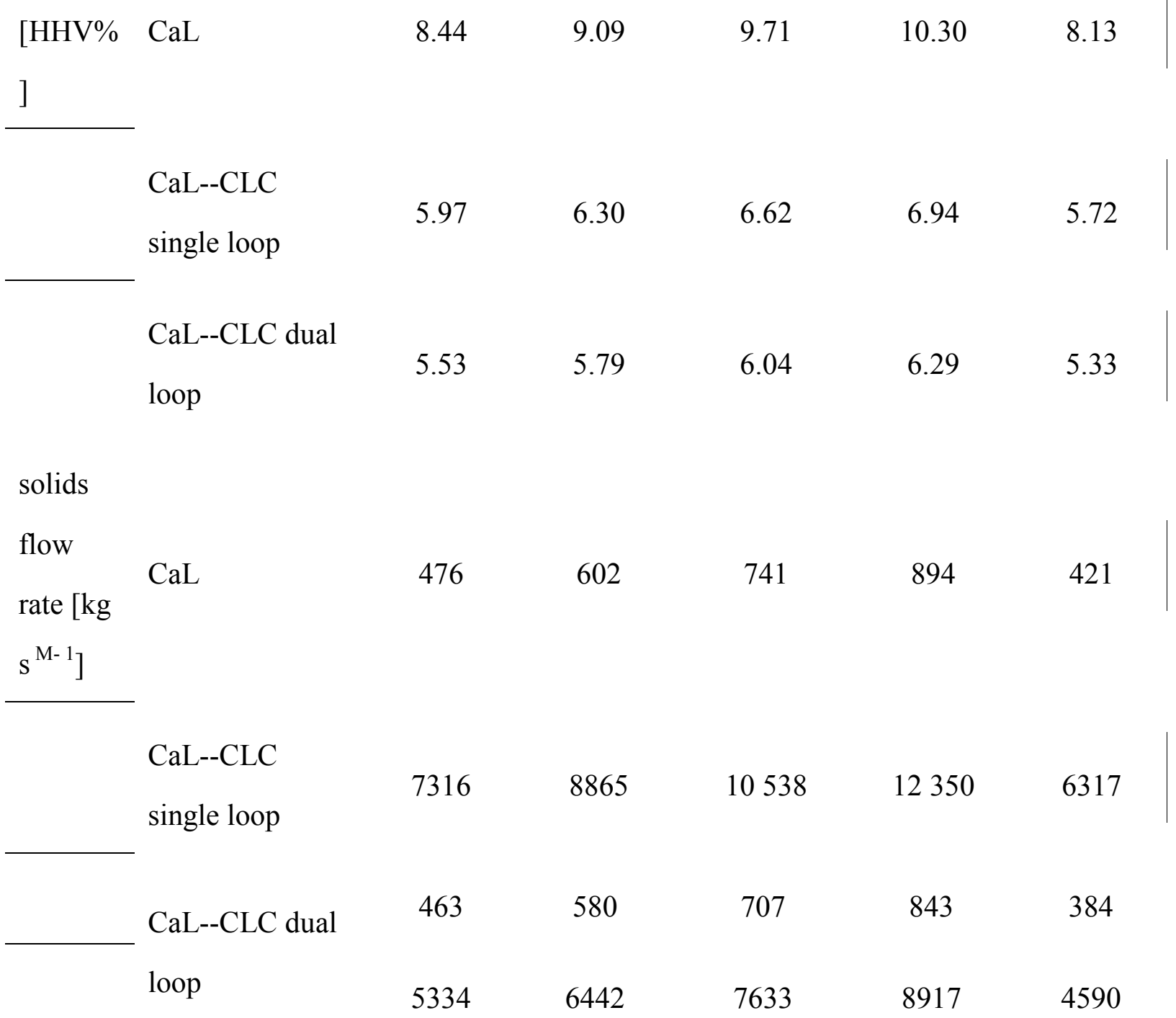

$\mathrm{CO}_{2}$

intensit

y [kg

$\mathrm{CO}_{2} /$ in

$\mathrm{CaL}$

375

280

186

92

420

$\mathrm{MW}_{\mathrm{e}}^{\mathrm{M}-}$

${ }^{1} \mathrm{~h}^{\mathrm{M}-1}$ ]

CaL--CLC

single loop

355

263

173

85

420 
CaL--CLC dual

loop

260

171

84

420

Table 9 Parameter analysis results----Multiple parameter optimization.

\begin{tabular}{|c|c|c|c|}
\hline Parameter & $\mathrm{CaL}$ & \multicolumn{2}{|c|}{ CaL--CLC } \\
\hline & & single loop & dual loop \\
\hline thermal power input $\left[\mathrm{MW}_{\text {th }}\right]$ & 618.6 & 520.6 & 486.8 \\
\hline extra net power output $\left[\mathrm{MW}_{\mathrm{e}}\right]$ & 79.1 & 92.4 & 90.5 \\
\hline penalty $[\mathrm{HHV} \%]$ & 8.13 & 5.84 & 5.34 \\
\hline \multirow[t]{2}{*}{ solids flow rate $\left[\mathrm{kg} \mathrm{s}^{\mathrm{M}-1}\right]$} & 428 & 5034 & $386 \mathrm{dp}$ (CLC side) \\
\hline & & & $3684 \mathrm{dp}$ (CLC side) \\
\hline $\mathrm{CO}_{2}$ intensity $\left[\mathrm{kg} \mathrm{CO}_{2} /\right.$ in $\left.\mathrm{MW}_{\mathrm{e}}^{\mathrm{M}-1} \mathrm{~h}^{\mathrm{M}-1}\right]$ & 420 & 420 & 420 \\
\hline
\end{tabular}

Table $10 \quad$ Flue gas conditions. ${ }^{[49]}$

Property Value

$\begin{array}{ll}T\left[{ }^{\circ} \mathrm{C}\right] & 57\end{array}$

flow rate $\left[\mathrm{kmol} \mathrm{h}^{\mathrm{M}-1}\right] \quad 74091$

$\mathrm{N}_{2}$ molar fraction $\quad 0.683$

$\mathrm{H}_{2} \mathrm{O}$ molar fraction $\quad 0.152$

$\mathrm{CO}_{2}$ molar fraction $\quad 0.135$ 
$\mathrm{O}_{2}$ molar fraction $\quad 0.024$

Ar molar fraction $\quad 0.006$

Table 11 Steam cycle conditions and efficiencies. ${ }^{[49]}$

Property Value

\begin{tabular}{lc}
\hline main steam & $593 \mathrm{dp}{ }^{\circ} \mathrm{C}, 24.1 \mathrm{MPa}$ \\
reheat steam $\left[{ }^{\circ} \mathrm{C}\right]$ & 593 \\
boiler efficiency [\%] & 88 \\
net plant efficiency [HHV \%] & 39.3
\end{tabular}

Table 12 Sorbent formulation.

Solid compounds CaL CaL--CLC

single loop dual loop

CaL side CLC side

$\begin{array}{lcccc}\mathrm{CaO}[\mathrm{wt} \%] & 90 & 86.2--89.2 & 90 & 0 \\ \mathrm{CuO}[\mathrm{wt} \mathrm{\%}] & 0 & 0.8--3.8 & 0 & 1.0--5.0 \\ \mathrm{Al}_{2} \mathrm{O}_{3}[\mathrm{wt} \%] & 10 & 10 & 10 & 95 \mathrm{dp}--99.0\end{array}$

